\title{
Unresectable Paraganglioma
}

National Cancer Institute

\section{Source}

National Cancer Institute. Unresectable Paraganglioma. NCI Thesaurus. Code C157126.

Paragang lioma that is not amenable to surgical resection. 